\title{
Randomized controlled trial of PosiFlow regulator with infusion clamp for reducing intravenous catheter plugging
}

\author{
Na Mi ${ }^{1 \#}$, Dahua Lan ${ }^{2 \#}$, Zhili Zhu ${ }^{3}$, Fengxia Yang ${ }^{1}$, Zhenling Wang ${ }^{1}$, Jing Wu ${ }^{1}$, Shuting Zhang ${ }^{1}$ Xi Huang ${ }^{1}$, \\ Wenjing $\mathrm{Li}^{1}$, Lingling Wei ${ }^{1}$, Jing $\mathrm{Li}^{1}$ \\ ${ }^{1}$ Department of Hepatobiliary Surgery, the Second Affiliated Hospital of Army Medical University, Chongqing, China; ${ }^{2}$ Medical Center of \\ Hematology, the Second Affiliated Hospital of Army Medical University, Chongqing, China; ${ }^{3}$ Dean's office, Army Medical University, Chongqing, \\ China \\ Contributions: (I) Conception and design: J Ling; (II) Administrative support: N Mi; (III) Provision of study materials or patients: J Wu; (IV) \\ Collection and assembly of data: N Mi, D Lan, Z Zhu, F Yang, Z Wang, J Wu, S Zhang, X Huang, W Li, L Wei; (V) Data analysis and \\ interpretation: All authors; (VI) Manuscript writing: All authors; (VII) Final approval of manuscript: All authors. \\ \#These authors contributed equally to this work. \\ Correspondence to: Jing Li. Department of Hepatobiliary Surgery, the Second Affiliated Hospital of Army Medical University, Chongqing 400037, \\ China. Email: xqyylj@163.com.
}

\begin{abstract}
Background: Intravenous (IV) catheter insertion may cause adverse reactions. It is necessary to investigate optimal methods for reducing blood return and extending the usage time of IV catheter by existing technologies. We investigated the efficacy of the PosiFlow regulator with an infusion clip for preventing IV catheter plugging due to venous blood return.
\end{abstract}

Methods: From January 2017 to August 2017, 960 patients requiring IV catheterization were recruited and by using the block randomization method randomly allocated to 4 groups ( $\mathrm{n}=240$ in each group): a control group receiving IV catheter with infusion clip; experimental group A receiving IV catheter without infusion clip; experimental group B receiving an IV catheter with the PosiFlow regulator; and experimental group $\mathrm{C}$ receiving an IV catheter with a PosiFlow regulator and infusion clip. The rates of catheter plugging and blood return were compared among groups.

Results: In different reasons for needle pulling, the rates of catheter plugging and blood return in experimental group C (Received IV catheterization with an infusion clip and PosiFlow regulato) were the lowest among all groups $(\mathrm{P}<0.05)$. In different puncture sites, forearm puncture further reduced $\mathrm{IV}$ catheter plugging in all groups compared to other puncture sites.

Conclusions: Catheter plugging and blood return can be significantly reduced by combining the PosiFlow regulator and an infusion clip, resulting in reduced medical costs and patient distress from catheter reinsertion.

Keywords! Intravenous catheter (IV catheter); infusion clip; PosiFlow; catheter obstruction

Submitted Dec 30, 2020. Accepted for publication Mar 03, 2021.

doi: 10.21037/apm-21-145

View this article at: http://dx.doi.org/10.21037/apm-21-145

\section{Introduction}

Intravenous (IV) catheters are widely used for clinical infusion; they reduce the pain caused by repeated puncture, facilitate emergency salvage, and improve medical staff efficiency (1). However, IV catheter insertion may cause adverse reactions such as puncture-site infection, liquid leakage, phlebitis, venous thrombosis, and subcutaneous hematoma. Furthermore, plugging of catheters may occur, which requires reinsertion. Indeed, reinsertion has been reported in $10-40 \%$ of patients receiving IV catheter (2). Catheter plugging may be caused by backflow of venous 
blood, patient movement, incomplete flushing after parenteral nutrition infusion, inappropriate needle type, too rapid injection, or improper selection of the tube-sealing solution (3). Of these, improper sealing operation by nurses, excessive movement of patients, and venous blood return due to high venous pressure in limbs after sealing are the most common causes.

In 1999, the PosiFlow regulator was introduced to China. Since then, compared to traditional tube sealing, it has been shown to significantly reduce the incidence of adverse events such as coagulation in the IV catheter hose and infusion particles and pollution caused by repeated puncture of the heparin cap. Its design, with dead space of only $0.06 \mathrm{~mL}$, is especially convenient for operation, while the cruciform diversion trench facilitates input of liquid. A vortex is generated by the internal design that automatically advances the liquid into the vein, thus preventing plugging caused by venous blood return, reducing complications caused by the tube-sealing solution and repeated puncture of the heparin cap, and extending the usage time of the IV catheter (4). However, according to Li (4), although the rate of blood return is significantly lower than before using PosiFlow, the incidence is still high. It is still necessary to examine the best methods for reducing blood return and extending the usage time of IV catheter using existing technologies. In this randomized controlled trial, we examined the efficacy of combining PosiFlow and an infusion clip for preventing catheter plugging caused by venous blood return.

We present the following article in accordance with the CONSORT reporting checklist (available at http://dx.doi. org/10.21037/apm-21-145).

\section{Methods}

\section{Participants}

From January 2017 to August 2017, 960 patients requiring IV catheter insertion during hospitalization in our department were recruited to this study. Inclusion criteria were as follows: (I) age under 70 years old, (II) more than 5 days of perfusion and infusion time plus at least 5 hours per day, (III) intact skin without scarring, inflammation, ulceration, edema or induration, and normal limb movement, (IV) conscious and able to sign the informed consent. Exclusion criteria were as follows: edema, hypoproteinemia, and coagulation dysfunction.

The study was approved by the Human Research
Ethics Committees of the Second Affiliated Hospital of Army Medical University (2019-065-01). All procedures performed in this study involving human participants were in accordance with the Declaration of Helsinki (as revised in 2013). Written informed consent was provided by the participants prior to randomization.

\section{Randomization}

Participants were randomly allocated to 4 groups by using the block randomization method ( $n=240$ per group), including a control group and experimental groups A, $\mathrm{B}$, and C. In the control group, an ordinary IV catheter was used and the infusion clip was closed after pulse tube sealing according to routine IV infusion protocols. Of the 3 experimental groups, group A received IV catheterization only, group B received IV catheterization with a PosiFlow regulator, and group $\mathrm{C}$ received IV catheterization with an infusion clip and PosiFlow regulator. Of the 960 participants, 21 quitted ( 8 in the control group and 13 in the experimental groups). The IV catheter was replaced by a ventral venous catheter (CVC) in 11 cases due to emergency surgery, and 6 participants were discharged on the day of catheterization. A peripherally inserted central catheter (PICC) was inserted under B-ultrasound guidance in 2 cases due to poor vascular conditions, and 2 cases were transferred to other institutions.

\section{Outcomes}

Catheter plugging and blood return were chosen as primary outcomes.

Blood return volume was calculated with the assistance of a medical doctor to ensure safety, accuracy, and feasibility. First, the effective cavity of the IV catheter was calculated experimentally by drawing $1 \mathrm{~mL}$ of $0.9 \%$ sodium chloride solution slowly into a $1 \mathrm{~mL}$ syringe and then slowly injecting it into the heparin cap until the effective cavity was filled. By this method, the effective cavity volume was determined to be $0.6 \mathrm{~mL}$. For calculation of blood return volume, $1 \mathrm{~mL}$ of $0.9 \%$ sodium chloride solution was drawn into a $1 \mathrm{~mL}$ syringe to simulate venous blood return, and then slowly injected into the needle tip of the IV catheter. The length of return was then measured as $0.1 \mathrm{~mL}$ normal saline over $2.8 \mathrm{~cm}$ of tubing, $0.2 \mathrm{~mL}$ over $8.9 \mathrm{~cm}$, and $0.3 \mathrm{~mL}$ over $13.6 \mathrm{~cm}$. The effective cavity of the heparin cap was $0.17 \mathrm{~mL}$ when filled with $0.9 \%$ sodium chloride solution. From these values, blood return volume was calculated for each 
participant. We then evaluated the relationship between blood return volume and catheter plugging.

In addition, a total of 9 observation indexes were recorded: (I) selection of puncture site, (II) duration of catheter usage, (III) causes of needle withdrawal, (IV) catheter plugging (yes/no), (V) blood return (yes/no), (VI) blood return volume, (VII) liquid leakage (yes/no), (VIII) phlebitis (yes/no), and (IX) grading of phlebitis. The causes of needle withdrawal included after infusion, over 96 hours, catheter plugging, liquid leakage, phlebitis, and pain. Phlebitis was graded as follows: Grade 0: no symptoms; Grade I: local pain, redness or edema, no cord-like changes and induration can be touched on the vein; Grade II: local pain, redness or edema, cord-like changes can be touched but no induration on the vein; Grade III: local pain, redness or edema, cord-like changes and induration can be touched on the vein; Grade IV: local pain, redness or edema, cordlike changes and induration can be touched on the vein, and the length is longer than $2.5 \mathrm{~cm}$.

After unified training, 10 nurses were assigned responsibility for measuring, observing, and recording these indexes daily.

\section{Statistical analysis}

All data were analyzed using the statistical software SPSS 20.0 (IBM Corp., Armonk, NY, USA). Continuous variables were expressed as mean \pm standard deviation and categorical variables as frequency and ratio. Group means were compared by independent sample $t$-test and ratios by chisquare $\left(\chi^{2}\right)$ test. A P value $<0.05$ was considered statistically significant.

\section{Results}

\section{Baseline characteristics of participants}

Participants requiring IV catheter insertion during hospitalization in our department were recruited from January 2017 to August 2017. There were no statistically significant differences in mean age, gender ratio, and primary disease distribution among the 4 groups (all $\mathrm{P}>0.05$, Table 1).

\section{Comparison of venous blood return rate, catheter plugging rate, and causes of needle withdrawal among groups}

The rates of catheter plugging and blood return were significantly different among the 4 groups. Experimental group $\mathrm{C}$ had the lowest catheter plugging and blood return rates among all groups (Table 2).

\section{Comparison of venous blood return and catheter plugging rate among different causes of needle withdrawal}

Subgroup analysis was performed to investigates the effect of different causes of needle withdrawal on blood return and catheter plugging. According to Table 3, after the completion of infusion, the rates of venous blood return and catheter plugging were still the lowest among all of the 4 groups. However, for other causes, there were no significant differences in the rates of venous blood return and catheter plugging among the 4 groups. In addition, for needle withdrawal due to catheter plugging, all participants had blood return (Table 3).

\section{Comparison of venous blood return and catheter plugging rates among different puncture sites}

The rates of venous blood return and catheter plugging were also compared among puncture sites, and were shown to be significantly lower in experimental group $\mathrm{C}$ than other groups when inserted in the opisthenar or forearm. In addition, the rates of blood return and catheter plugging were the lowest in forearm. However, for other puncture sites, there were no significant differences in the rates of venous blood return and catheter plugging among the 4 groups (Table 4). Therefore, we advocate the forearm as the preferred puncture site for IV catheter insertion.

\section{Discussion}

Venous blood return is a common problem during the clinical application of IV catheters. A baseline survey in our department demonstrated that blood return occurred during $60.7 \%$ of IV catheter applications. Further, venous blood return is a common cause for needle withdrawal. However, blood return alone is not a sufficient condition for withdrawal. In the current trial, the main reason for needle withdrawal was catheter plugging due to venous blood return. However, not all cases of venous blood return resulted in catheter plugging. Thus, it is likely that plugging depends on some additional factors such as actual blood concentration in the catheter, which would increase the chance of clogging due to coagulation. Unfortunately, the current method for calculation of blood return volume 
Table 1 Baseline characteristics of participants

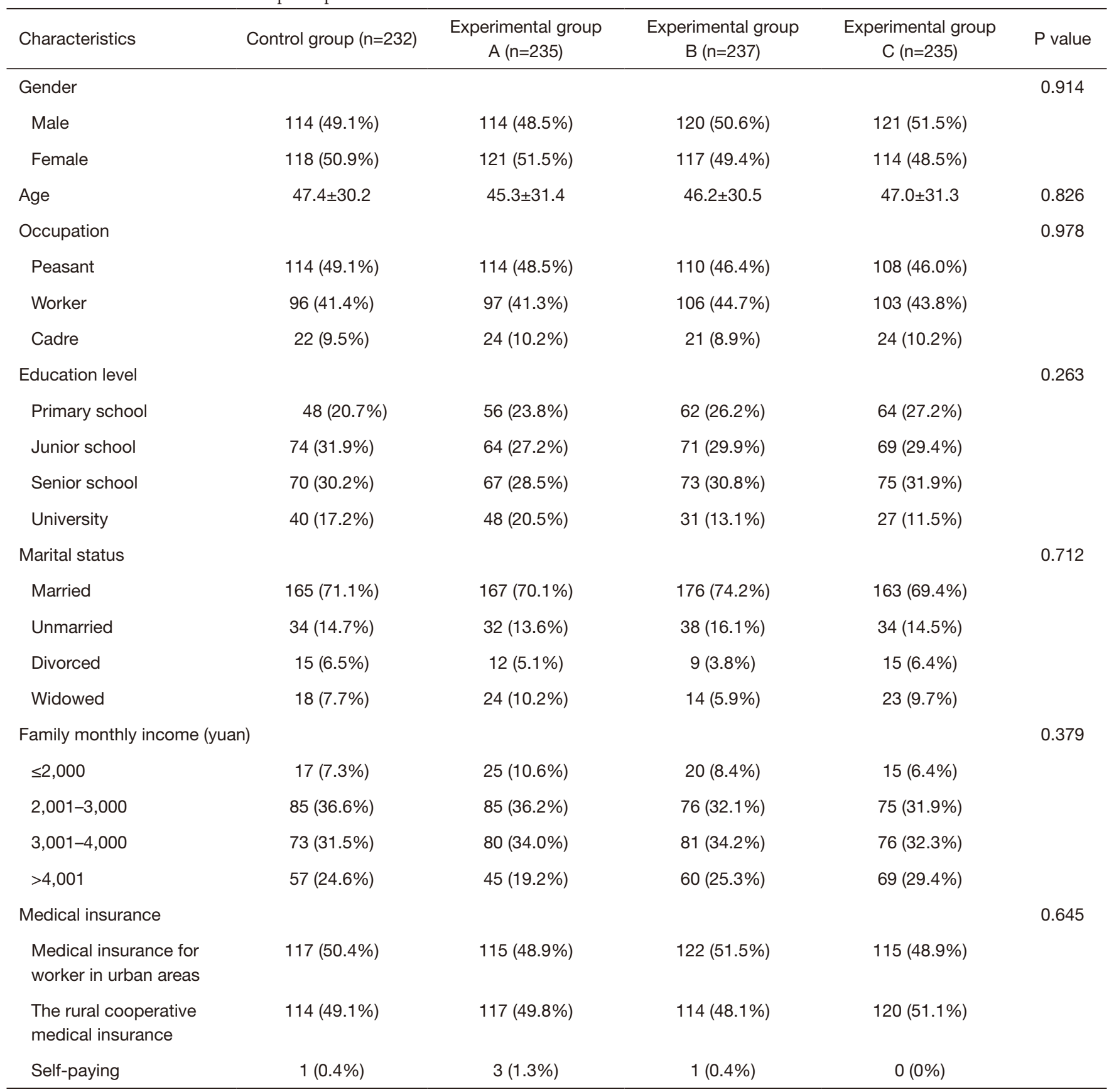

Table 2 Blood return and catheter plugging rates in different groups

\begin{tabular}{lcccccc}
\hline Endpoints & Control group $(\mathrm{n}=232)$ & $\begin{array}{c}\text { Experimental group } \\
\mathrm{A}(\mathrm{n}=235)\end{array}$ & $\begin{array}{c}\text { Experimental group } \\
\mathrm{B}(\mathrm{n}=237)\end{array}$ & $\mathrm{Experimental} \mathrm{group}$ & $\mathrm{C}(\mathrm{n}=235)$ & $\chi^{2}$ \\
\hline Blood return & $117(50.4 \%)$ & $114(48.5 \%)$ & $86(36.3 \%)$ & $63(26.8 \%)$ & 35.788 & $<0.001$ \\
Catheter plugging & $58(25.0 \%)$ & $51(21.7 \%)$ & $39(16.5 \%)$ & $19(8.1 \%)$ & 26.134 & $<0.001$ \\
\hline
\end{tabular}


Table 3 Comparison of blood return and catheter plugging rates in different causes of needle withdrawal

\begin{tabular}{|c|c|c|c|c|c|c|}
\hline $\begin{array}{l}\text { Different causes of needle } \\
\text { withdrawal }\end{array}$ & $\begin{array}{l}\text { Control group } \\
\qquad(\mathrm{n}=232)\end{array}$ & $\begin{array}{l}\text { Experimental group } \\
\qquad A(n=235)\end{array}$ & $\begin{array}{l}\text { Experimental group } \\
\qquad B(n=237)\end{array}$ & $\begin{array}{l}\text { Experimental group } \\
\qquad C(n=235)\end{array}$ & $\chi^{2}$ & $P$ value \\
\hline Completion of infusion & 59 & 79 & 87 & 127 & & \\
\hline Catheter plugging & $11(18.6 \%)$ & $14(17.2 \%)$ & $9(10.3 \%)$ & $3(2.4 \%)$ & 17.483 & $<0.001$ \\
\hline Catheter plugging & 27 (100\%) & $22(100 \%)$ & $23(100 \%)$ & $13(100 \%)$ & $\mathrm{N} / \mathrm{A}$ & $\mathrm{N} / \mathrm{A}$ \\
\hline Liquid leakage & 64 & 57 & 50 & 39 & & \\
\hline Blood return & $20(31.3 \%)$ & $17(29.8 \%)$ & $13(26.0 \%)$ & $9(23.1 \%)$ & 0.995 & 0.803 \\
\hline Catheter plugging & $2(14.3 \%)$ & $2(18.2 \%)$ & $1(10.0 \%)$ & $0(0 \%)$ & 1.799 & 0.615 \\
\hline Pain & 56 & 49 & 54 & 40 & & \\
\hline Blood return & $23(41.1 \%)$ & $19(38.8 \%)$ & $15(27.8 \%)$ & $9(22.5 \%)$ & 5.035 & 0.169 \\
\hline Catheter plugging & $9(16.1 \%)$ & $6(12.2 \%)$ & $3(5.5 \%)$ & $1(2.5 \%)$ & 6.470 & 0.091 \\
\hline Other causes & 12 & 17 & 13 & 7 & & \\
\hline Blood return & $1(8.3 \%)$ & $2(11.8 \%)$ & $1(7.7 \%)$ & $0(0 \%)$ & 28.296 & $<0.001$ \\
\hline Catheter plugging & $0(0 \%)$ & $0(0 \%)$ & $0(0 \%)$ & $0(0 \%)$ & N/A & $\mathrm{N} / \mathrm{A}$ \\
\hline
\end{tabular}

cannot calculate the blood concentration, a limitation that requires further studies.

At present, the majority of models of IV catheters adopted by our department are equipped with infusion clips, which should be closed when using $0.9 \%$ sodium chloride solution or pre-flushing sealing solution. However, there are no definitive rules on whether it is necessary to clamp the infusion clip after using the PosiFlow, nor clear stipulations provided by the Infusion Treatment Nursing Practice Guideline and Rules. According to the relevant literature, it is reasonable to disconnect the infusion connector after pulse sealing without clamping the infusion clip while using the PosiFlow. During clinical infusion, we found that a drop of liquid overflowed from the tip of the catheter after using the PosiFlow and infusion clip, achieving the effect of secondary positive pressure sealing and helping prevent venous blood return. After applying this improved method, the rate of catheter plugging for any reason was only $2.36-5.12 \%$. Furthermore, the usage of an infusion clip can further enhance the benefits of the PosiFlow regulator for preventing venous catheter plugging caused by blood return. This procedure should be a standard operating procedure for routine IV catheter insertion (5).

The choice of puncture site also influenced the rate of IV catheter plugging caused by venous blood return, with significantly lower incidence at the forearm compared to other puncture sites. Thus, whenever possible, the nurse should insert an IV catheter into the forearm to reduce the risk of catheter plugging due to venous blood return (6). This is consistent with the recommendations of the Infusion Treatment Nursing Practice Guidelines and Rules (2016 edition).

This methodology is simple, effectively reduces the rate of IV catheter plugging by venous blood return, and offers the additional benefit of being more cost effective. On average, 80 (107.8 RMB) fewer IV catheter sets and PosiFlow regulators were required every month in group C, which would save more than 100,000 RMB annually. Use of the PosiFlow and clip also reduced the number of syringes $(0.35 \mathrm{RMB})$ and $0.9 \%$ sodium chloride solution 
Table 4 Comparison of blood return and catheter plugging rates at different puncture sites

\begin{tabular}{|c|c|c|c|c|c|c|}
\hline Different puncture sites & $\begin{array}{l}\text { Control group } \\
\qquad(n=232)\end{array}$ & $\begin{array}{l}\text { Experimental group } \\
\qquad A(n=235)\end{array}$ & $\begin{array}{l}\text { Experimental group } \\
\qquad B(n=237)\end{array}$ & $\begin{array}{l}\text { Experimental group } \\
\qquad C(n=235)\end{array}$ & $\chi^{2}$ & $P$ value \\
\hline Opisthenar & 92 & 95 & 98 & 97 & & \\
\hline Catheter plugging & $21(22.8 \%)$ & $20(21.1 \%)$ & $15(15.3 \%)$ & $6(6.2 \%)$ & 11.829 & 0.048 \\
\hline Catheter plugging & $10(23.3 \%)$ & $9(22.5 \%)$ & $7(17.5 \%)$ & $5(11.9 \%)$ & 2.271 & 0.518 \\
\hline Forearm & 65 & 67 & 62 & 66 & & \\
\hline Blood return & $25(38.5 \%)$ & $23(34.3 \%)$ & $18(29.0 \%)$ & $13(19.7 \%)$ & 6.014 & 0.041 \\
\hline Catheter plugging & $7(41.2 \%)$ & $4(25.0 \%)$ & $4(21.1 \%)$ & $2(12.5 \%)$ & 3.864 & 0.277 \\
\hline Elbow & 15 & 17 & 18 & 14 & & \\
\hline Blood return & $12(80.0 \%)$ & $13(76.5 \%)$ & $10(55.6 \%)$ & $6(42.9 \%)$ & 6.092 & 0.107 \\
\hline Catheter plugging & $7(16.7 \%)$ & $5(29.4 \%)$ & $4(22.2 \%)$ & $2(14.3 \%)$ & 4.202 & 0.240 \\
\hline
\end{tabular}

(1.46 RMB) discarded due to catheter plugging, for a total savings of 1,781.04 RMB. The normal puncture time for each IV catheter is around 10 minutes, so this method will also save nurses 9,840 minutes per year in time required for re-puncture, equivalent to 20.5 working days. Further, 2 minutes on average is required for IV catheter flushing necessitated by catheter plugging, so this method will save an additional 1,968 minutes per year, equivalent to 4.1 working days.

\section{Conclusions}

The use of PosiFlow with an infusion clip will reduce both material and labor costs as well as staff time.

\section{Acknowledgments}

Funding: None.

\section{Footnote}

Reporting Checklist: The authors have completed the CONSORT reporting checklist. Available at http://dx.doi. org/10.21037/apm-21-145
Data Sharing Statement: Available at http://dx.doi. org/10.21037/apm-21-145

Conflicts of Interest: All authors have completed the ICMJE uniform disclosure form (available at http://dx.doi. org/10.21037/apm-21-145). The authors have no conflicts of interest to declare.

Ethical Statement: The authors are accountable for all aspects of the work in ensuring that questions related to the accuracy or integrity of any part of the work are appropriately investigated and resolved. The study was approved by the Human Research Ethics Committees of the Second Affiliated Hospital of Army Medical University (2019-065-01). All procedures performed in this study involving human participants were in accordance with the Declaration of Helsinki (as revised in 2013). Written informed consent was provided by the participants prior to randomization.

Open Access Statement: This is an Open Access article distributed in accordance with the Creative Commons Attribution-NonCommercial-NoDerivs 4.0 International License (CC BY-NC-ND 4.0), which permits the non- 
commercial replication and distribution of the article with the strict proviso that no changes or edits are made and the original work is properly cited (including links to both the formal publication through the relevant DOI and the license). See: https://creativecommons.org/licenses/by-nc-nd/4.0/.

\section{References}

1. Guerrero MA. National evaluation of safety peripheral intravenous catheters in a clinician-led project. Br J Nurs 2019;28:S29-S32.

2. Carr PJ, Higgins NS, Cooke ML, et al. Tools, Clinical Prediction Rules, and Algorithms for the Insertion of Peripheral Intravenous Catheters in Adult Hospitalized Patients: A Systematic Scoping Review of Literature. J

Cite this article as: Mi N, Lan D, Zhu Z, Yang F, Wang Z, Wu J, Zhang S, Huang X, Li W, Wei L, Li J. Randomized controlled trial of PosiFlow regulator with infusion clamp for reducing intravenous catheter plugging. Ann Palliat Med 2021;10(3):3135-3141. doi: 10.21037/apm-21-145
Hosp Med 2017;12:851-8.

3. Chau CT, Prielipp RC, Wahr JA. Prevention of Thrombophlebitis in Peripheral Intravenous Catheters: The Butterfly Effect. Anesth Analg 2018;127:1287-8.

4. Li N. Application of posiflow in the use of safe intravenous catheter infusion. Nurs J Chin Army 2009;26:4.

5. Nickel B. Peripheral Intravenous Access: Applying Infusion Therapy Standards of Practice to Improve Patient Safety. Crit Care Nurse 2019;39:61-71.

6. Millington SJ, Hendin A, Shiloh AL, et al. Better With Ultrasound: Peripheral Intravenous Catheter Insertion. Chest 2020;157:369-75.

(English Language Editor: J. Jones) 